\title{
Role of the learning curve in very high-risk patients treated with MitraClip device for functional mitral regurgitation: a single-centre experience
}

\author{
Adrian Kłapyta $^{1 *}$, Jerzy Pręgowski ${ }^{2 *}$, Zbigniew Chmielak $^{2}$, Piotr Szymański ${ }^{2}$, Jarosław Skowroński ${ }^{2}$, \\ Patrycjusz Stokłosa², Krzysztof Kukuła ${ }^{2}$, Mariusz Kłopotowski², Paweł Tyczyński ${ }^{2}$, Paweł Jelski ${ }^{2}$, \\ Łukasz Kalińczuk², Kacper Milczanowski², Adam Witkowski \\ 'Freelance, Abbott Therapy Specialist MitraClip \\ ${ }^{2}$ Department of Interventional Cardiology and Angiology, Institute of Cardiology, Warsaw, Poland \\ *Both authors equally contributed to the study.
}

\section{INTRODUCTION}

The MitraClip device allows a minimally invasive repair of mitral regurgitation (MR). The available data confirm the safety and efficacy of the procedure despite its complexity [1-9]. The aim of our study was to assess the role of the learning curve in the MitraClip procedure in patients with functional MR.

\section{METHODS}

The study summarises a single-centre experience on all MitraClip procedures performed from 2012 to 2017. In this research, a retrospective analysis of clinical data was performed. The technical aspects of the MitraClip device implantation performed under transoesophageal echocardiography (TEE) guidance were described previously [1]. There were three interventional cardiologists (A.W., Z.C., and J.P.) including one (J.P.) who attended all the procedures guided by the same echocardiographer (P.S.). Except for the first two procedures, we used the same TEE device (General Electric Healthcare, Chicago, IL, USA) with the three-dimensional option. The clips were finally implanted and released if a significant reduction of MR was achieved without creating significant stenosis defined as a mean mitral gradient $(\mathrm{MMG}) \geq 5 \mathrm{mmHg}$. The total device time was defined as the period between transseptal puncture and removal of a steerable guiding catheter from the femoral vein. Prior to discharge, all patients underwent control transthoracic echocardiography (TTE) with a focus on the stability of the clip position, MR grade, and MMG. An uncomplicated MitraClip implantation and MR reduction to grade $\leq 2+$ assessed on the pre-discharge TTE was defined as a procedural success. All patients were scheduled for 30-day clinical follow-up. The procedure-related variables as well as immediate and 30-day results were compared between two groups of patients treated in two consecutive time periods. Continuous data were presented as mean \pm standard deviation. We used either the independent-samples t test or the Mann-Whitney test to compare continuous variables. Categorical variables were presented as numbers and percentages and were compared using the $\chi^{2}$ test.

\section{RESULTS AND DISCUSSION}

Between May 2012 and December 2017, we performed 53 MitraClip procedures (43 men; mean age, $67.8 \pm 7.2$ years). All subjects who underwent the procedure were diagnosed with heart failure and significant functional MR. Most (87\%) patients were in functional New York Heart Association (NYHA) class III or IV. The mean left ventricular ejection fraction (LVEF) was $28 \% \pm 9 \%$. The majority of patients had pulmonary hypertension with a mean pulmonary artery systolic pressure of $52 \pm 14 \mathrm{mmHg}$.

In the first four years (2012-2016) of the MitraClip programme, we performed 26 implantations (4-6 procedures per year; group 1). In 2017 the number of procedures significantly increased, and 27 patients were treated (group 2). The baseline demographic and clinical characteristics of patients were similar in both groups, except lower LVEF in group $2(25 \% \pm 10 \%$ vs. $31 \% \pm 7 \% ; p=0.03)$.

Within 30 days of the procedure, three $(5.6 \%)$ patients died (one patient from group 1 and two patients from group 2; 


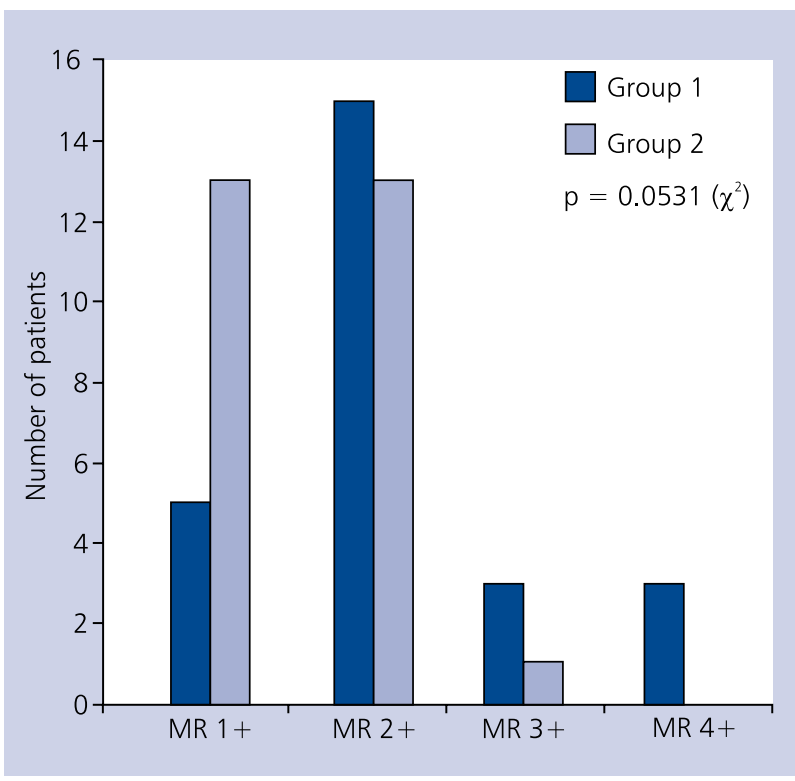

Figure 1. Residual mitral regurgitation (MR) after MitraClip procedure in both study groups

$p=0.6$ ). One death (group 1) was directly related to the MitraClip procedural complication (leaflet rupture). In group 2 two deaths occurred: one due to deteriorating heart failure and one sudden cardiac death. Two patients from group 1 required mitral valve surgery, including one urgent case in a patient with acute leaflet rupture. A partial clip detachment occurred in two patients from group 1 and in two patients from group $2(p=0.5)$.

In the whole study group of patients who survived 30 days, there were 16 subjects in NYHA class III or IV as compared with 46 patients with severe symptoms prior to the intervention $(p<0.001)$. However, at 30 days the number of patients in functional NYHA class $>2$ was similar in group 1 and group 2 (10 and 6 , respectively; $p=0.6$ ).

The total device time and fluoroscopy time were shorter in group 2 than in group $1(166 \pm 62.5 \mathrm{~min}$ vs. $106.3 \pm 44.9 \mathrm{~min} ; \mathrm{p}=0.0002$ and $61.5 \pm 25.1 \mathrm{~min}$ vs. $41.0 \pm 18.9 \mathrm{~min} ; \mathrm{p}=0.0014$, respectively), while the number of clips implanted was similar in group 1 and group 2 $(1.8 \pm 0.6$ and $1.9 \pm 0.5$, respectively; $p=0.8)$. The residual MR after the procedure was smaller in group 2 (Fig. 1). The procedural success was achieved in $77 \%$ of patients from group 1 and in 96\% of those from group 2 ( $p=0.039$ ). None of the patients had MMG $\geq 5 \mathrm{mmHg}$ on TEE performed at the end of the procedure, but in the postprocedural TTE moderate iatrogenic mitral stenosis was found with a similar prevalence in both study groups (4 [15\%] in group 1 and $6[22 \%]$ in group $2 ; p=0.5)$.

The major finding from the current study is that the MitraClip procedure for functional MR requires a significant learning curve. As the team's experience increased, the procedural time shortened and the acute results improved. However, we did not identify any impact of the learning curve on the incidence of procedural complications, MMG, or functional NYHA classification.

Interestingly, even though intuitively the MitraClip procedure requires a learning curve for its complexity, data on the relation between the operators' experience and the procedure outcomes are conflicting [7-9]. Ledwoch et al. [7] did not report any impact of the learning curve on procedural safety, time, and acute MR reduction. The authors suggested that a strict proctoring system allows optimal results even during initial experience with the device. On the other hand, Schillinger et al. [8] and Eleid et al. [9], similarly to our data, reported a significant effect of the learning curve on the procedural time. However, neither Schillinger et al. [8] nor Eleid et al. [9] noted a significant influence of case experience on the extent of MR reduction. Interestingly, in both those studies, increasing experience with the device translated into a lower rate of complications, while in our experience the complication rate was constant. The possible explanation of the differences between our study and previous reports could be different MR aetiology (functional in our group vs. functional or primary in previous papers).

In our group MMG measured within a few days of the procedure exceeded $5 \mathrm{mmHg}$ in about $20 \%$ of patients even though it was lower immediately after the procedure. This finding is in line with the report by Boerlage-van Dijk et al. [10], who also noticed a significantly higher gradient in daily life after the procedure than during MitraClip implantation. Importantly, several authors found that higher post-procedural mitral gradients are linked to worse clinical outcome [11, 12]. According to our data, the mitral valve gradient was not affected by the learning curve. This is new information because so far there have been no data on the impact of case experience on the risk of iatrogenic mitral stenosis. It is possible that avoidance of an increased MMG is part of the procedure that will remain the "most resistant" to the learning curve, because there will always be a need for compromise between optimal MR reduction and risk of significant iatrogenic stenosis.

In conclusion, the learning curve significantly influences procedural time and acute results in very high-risk patients with functional MR treated with MitraClip.

\section{Conflict of interest: none declared}

\section{References}

1. Feldman T, Foster E, Glower D, et al. Percutaneous repair or surgery for mitral regurgitation. N Engl J Med. 2011; 364(15): 1395-1406, doi: 10.1056/nejmoa1009355, indexed in Pubmed: 15302782

2. Vemulapalli S, Lippmann SJ, Krucoff M, et al. Cardiovascular events and hospital resource utilization pre- and post-transcatheter mitral valve repair in high-surgical risk patients. Am Heart J. 2017; 189: 146-157, doi: 10.1016/j.ahj.2017.04.012, indexed in Pubmed: 28625371 
3. Feldman T, Kar S, Elmariah S, et al. Randomized comparison of percutaneous repair and surgery for mitral regurgitation: 5-year results of EVEREST II. J Am Coll Cardiol. 2015; 66(25): 2844-2854, doi: 10.1016/j.jacc.2015.10.018, indexed in Pubmed: 26718672 .

4. Maisano F, Franzen O, Baldus S, et al. Percutaneous mitral valve interventions in the real world: early and 1-year results from the ACCESS-EU, a prospective, multicenter, nonrandomized post-approval study of the MitraClip therapy in Europe. J Am Coll Cardiol. 2013; 62(12): 1052-1061, doi: 10.1016/ /j.jacc.2013.02.094, indexed in Pubmed: 23747789.

5. Franzen O, Baldus S, Rudolph V, et al. Acute outcomes of MitraClip therapy for mitral regurgitation in high-surgical-risk patients: emphasis on adverse valve morphology and severe left ventricular dysfunction. Eur Heart J. 2010; 31(11): 1373-1381, doi: 10.1093/eurheartj/ehq050, indexed in Pubmed: 20219746.

6. Nickenig G, Estevez-Loureiro R, Franzen O, et al. Transcatheter Valve Treatment Sentinel Registry Investigators of the EURObservational Research Programme of the European Society of Cardiology. Percutaneous mitral valve edge-to-edge repair: in-hospital results and 1-year follow-up of 628 patients of the 2011-2012 Pilot European Sentinel Registry. J Am Coll Cardiol. 2014; 64(9): 875-884, doi: 10.1016/j.jacc.2014.06.1166, indexed in Pubmed: 25169171.

7. Ledwoch J, Franke J, Baldus S, et al. Impact of the learning curve on outcome after transcatheter mitral valve repair: results from the German Mitral Valve Registry. Clin Res Cardiol. 2014; 103(11): 930-937, doi: 10.1007/s00392-014-0734-y, indexed in Pubmed: 24924580.

8. Schillinger W, Athanasiou T, Weicken N, et al. Impact of the learning curve on outcomes after percutaneous mitral valve repair with MitraClip and lessons learned after the first 75 consecutive patients. Eur J Heart Fail. 2011; 13(12): 1331-1339, doi: 10.1093/eurjhf/hfr141, indexed in Pubmed: 22024027.

9. Eleid MF, Reeder GS, Malouf JF, et al. The Learning Curve for Transcatheter Mitral Valve Repair With MitraClip. J Interv Cardiol. 2016; 29(5): 539-545, doi: 10.1111/joic.12326, indexed in Pubmed: 27696544.

10. Boerlage-van Dijk K, van Riel AC, de Bruin-Bon RH, et al. Mitral inflow patterns after MitraClip implantation at rest and during exercise. J Am Soc Echocardiogr. 2014; 27(1): 24-31.e1, doi: 10.1016/j.echo.2013.09.007, indexed in Pubmed: 24161483.

11. Neuss M, Schau T, Isotani A, et al. Elevated mitral valve pressure gradient after MitraClip implantation deteriorates long-term outcome in patients with severe mitral regurgitation and severe heart failure. JACC Cardiovasc Interv. 2017; 10(9): 931-939, doi: 10.1016/j.jcin.2016.12.280, indexed in Pubmed: 28473116.

12. Utsunomiya H, Itabashi Y, Kobayashi S, et al. Effect of percutaneous edge-to-edge repair on mitral valve area and its association with pulmonary hypertension and outcomes. Am J Cardiol. 2017; 120(4): 662-669, doi: 10.1016/j.amjcard.2017.05.036, indexed in Pubmed: 28673638.

Cite this article as: Kłapyta A, Pręgowski J, Chmielak Z, et al. Role of the learning curve in very high-risk patients treated with MitraClip device for functional mitral regurgitation: a single-centre experience. Kardiol Pol. 2018; 76(11): 1564-1566, doi: 10.5603/KP.a2018.0192. 